\title{
Rule-based Mamdani-type fuzzy modelling of thermal performance of fin- tube evaporator under frost conditions
}

\author{
Dilek Nur Ozen¹, Kemal Altinisik², Kevser Dincer ${ }^{2}$, Ali Ates², Ahmet Ali Sertkaya ${ }^{3}$ and Muhammed Emin Tolu4, a \\ ${ }^{1}$ Necmettin Erbakan University, Faculty of Engineering and Architecture, Department of Mechanical Engineering, Meram, Konya, Turkey \\ ${ }^{2}$ Selcuk University, Faculty of Engineering, Department of Mechanical Engineering, Selcuklu, Konya, Turkey \\ ${ }^{3}$ Necmettin Erbakan University, Faculty of Seydisehir Ahmet Cengiz Engineering, Department of Mechanical Engineering,42360, Seydisehir, \\ Konya, Turkey \\ ${ }^{4}$ Karamanoglu Mehmetbey University, Faculty of Engineering, Department of Mechanical Engineering, Karaman, Turkey
}

\begin{abstract}
Frost formation brings about insulating effects over the surface of a heat exchanger and thereby deteriorating total heat transfer of the heat exchanger. In this study, a fin-tube evaporator is modeled by making use of Rule-based Mamdani-Type Fuzzy (RBMTF) logic where total heat transfer, air inlet temperature of $2{ }^{\circ} \mathrm{C}$ to $7{ }^{\circ} \mathrm{C}$ and four different fluid speed groups (ua1 $=1 ; 1.44 ; 1.88 \mathrm{~m} \mathrm{~s}-1$, ua2 $=2.32 ; 2.76 \mathrm{~m} \mathrm{~s}-1$, ua3 $=3.2 ; 3.64 \mathrm{~m} \mathrm{~s}-1$, ua4=4.08; $4.52 ; 4.96 \mathrm{~m} \mathrm{~s}-1$ ) for the evaporator were taken into consideration. In the developed RBMTF system, outlet parameter UA was determined using inlet parameters Ta and ua. The RBMTF was trained and tested by using MATLAB ${ }^{\circledR}$ fuzzy logic toolbox. $\mathrm{R}^{2}(\%)$ for the training data and test data were found to be $99.91 \%$. With this study, it has been shown that RBMTF model can be reliably used in determination of a total heat transfer of a fin-tube evaporator.
\end{abstract}

\section{Introduction}

An evaporator is a device operating by the vapor compression refrigerating cycle principle and is used for cooling purposes (like cooling the cabin of a refrigerator). If the temperature of the evaporator surface in a refrigerator is below the freezing temperature of the moisture within the air, then frosting forms on the evaporator surface. If the frost keeps staying below the freezing point, then frost will form a layer on the surface. The formed layer acts as an insulator by increasing thermal resistance and thereby leading to dropping the thermal performance of the evaporator [1]. In the existing literature, there are many numerical and experimental studies on the performance of finned tube heat exchangers operating under frosting conditions.

Fuzzy logic is a mathematical discipline that we use every day and helps us to reach the structure in which we interpret our own behaviors. Fuzzy expert system is an expert system that uses a collection of fuzzy rules, instead of Boolean logic, to reason about data [2]. Over the last few years, there have been many investigations on the application of fuzzy logic. Some are briefly mentioned below. Tasdemir et al. [3] studied artificial neural network (ANN) and fuzzy expert system (FES) and their comparison for prediction of performance and emission parameters on a gasoline engine. Tosun and Dincer [4] carried out a study on modelling of a thermal insulation system based on the coldest temperature conditions by using artificial neural networks to determine the performance of building for wall types in Turkey They noted that in this study the ANN approach has been applied accurately to model for the thickness of thermal insulation performance system on the coldest temperature basis for wall types that are mostly used for buildings in Turkey. Tosun et al. [5] investigated Rulebased Mamdani-type fuzzy modeling (RBMTF) of thermal performance of multi-layer precast concrete panels used in residential buildings in Turkey. They reported that prediction of RBMTF modeling approach can be successfully used for the modeling of thermal performance of multi-layer precast concrete panels used in residential buildings in Turkey.

In this study, the performance of a finned tube evaporator under frost forming conditions was modeled by making use of RBMTF technique. Input parameters taken were air entrance temperature and inlet speed while the output parameter was the total heat transfer of the evaporator. When the experimental data were compared with the data obtained from the RBMTF technique, it was found that the two are in correlation with each other. The UA values at different air operating conditions which were not studied experimentally were estimated with the RBMTF technique.

\section{Experimental setup}

The schematic diagram of the experimental system that shows evaporators' total heat transfer in a no-frost refrigerator operating under frosting conditions is given in Figure 1. The experimental setup consists of an air tunnel, refrigerating system and a data logger. The outside diameter of the test evaporator pipe inserted into the air

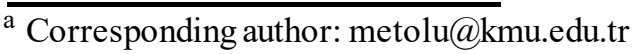


tunnel is $8 \mathrm{~mm}$, its thickness is $0.8 \mathrm{~mm}$ and the fin thickness is $0.12 \mathrm{~mm}$. during the tests, the air was drawn by a fan from an aperture and circulated around the channel. In order to regulate the air operating conditions within the air tunnel, a demoisturizer, a cooler, a heater and a humidifier were used. The air amount sent to the evaporator was adjusted with a damper. Airstream straightener was used to maintain homogeneous air dispersion to the evaporator. During the experiments, air inlet and outlet temperatures and the relative humidity were measured with a temperature-humidity measuring device while the air speed was measured with the anemometer.

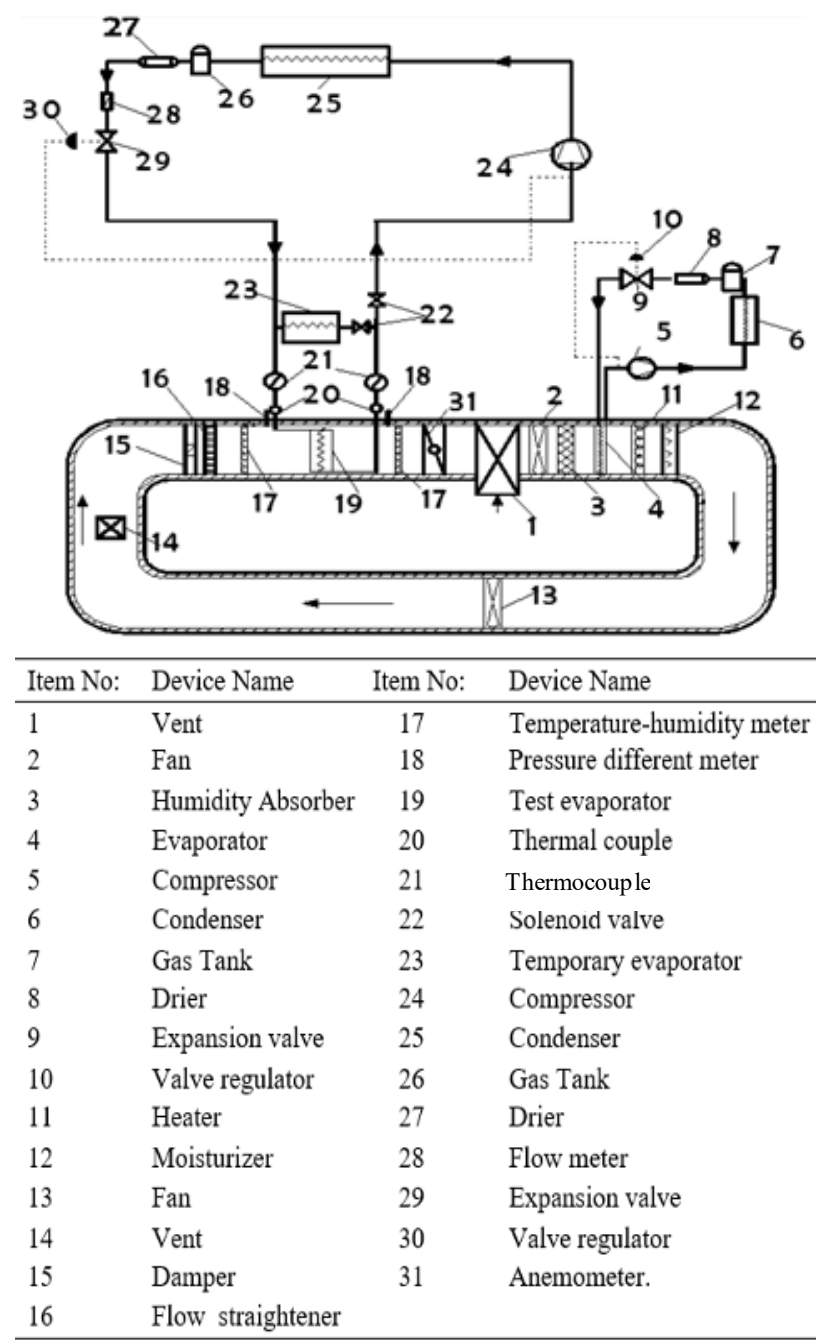

Figure 1. Schematic presentation of experimental system

\subsection{Air enthalpy at the evaporator inlet and outlet}

The enthalpy of the moisture entering the evaporator is found by using Eq. (1) below:

$i_{a}=c_{p a} T_{a}+w_{a}\left(2501.3+1.82 T_{a}\right)$

Here, $\mathrm{c}_{\mathrm{pa}}, \mathrm{T}_{\mathrm{a}}$ and $\mathrm{w}_{\mathrm{a}}$ represent specific heat capacity of air, temperature and specific humidity of the air respectively.

\subsection{Heat transfer for air side}

The air temperature on the medium where the channel exists is higher than that of the air within the channel. For this reason, there is a heat gain on the test zone of the channel. Air transfer on the air side is found with Eq. (2).

$$
\mathrm{q}_{\mathrm{a}}=\dot{\mathrm{m}}_{\mathrm{a}}\left(\mathrm{i}_{\mathrm{ai}}-\mathrm{i}_{\mathrm{ao}}\right)-(\mathrm{UA})_{\text {channel }}\left(\mathrm{T}_{\mathrm{e}}-\mathrm{T}_{\mathrm{s}}\right)
$$

Where, $\mathrm{m}_{\mathrm{a}}, \mathrm{i}_{\mathrm{ai}}, \mathrm{i}_{\mathrm{a} o}$ and (UA) channel are respectively the inlet air mass flow, inlet air enthalpy, outlet air enthalpy and overall heat transfer coefficient of channel. $T_{e}$ and $T_{s}$ are the environment and surface temperatures of the channel respectively.

\subsection{Heat transfer for refrigerant side}

The heat transferred from the refrigerant is calculated from the following equation.

$$
\mathrm{q}_{\mathrm{r}}=\dot{\mathrm{m}}_{\mathrm{r}}\left(\mathrm{i}_{\mathrm{ro}}-\mathrm{i}_{\mathrm{ri}}\right)
$$

Here $\dot{\mathrm{m}}_{\mathrm{r}}, \mathrm{i}_{\mathrm{ri}}$ and $\mathrm{i}_{\text {ro }}$ respectively, represent the mass flow rate of the refrigerant, evaporator inlet and outlet enthalpies.

\subsection{Evaporator's overall heat transfer coefficient}

Eq. (4) below, was obtained by making use of the arithmetic mean of the evaporator's heat capacity $\left(\mathrm{q}_{\mathrm{m}}\right)$, refrigerant's heat capacity $\left(\mathrm{q}_{\mathrm{r}}\right)$ and the heat capacity on the air

$\mathrm{q}_{\mathrm{m}}=\frac{\mathrm{q}_{\mathrm{a}}+\mathrm{q}_{\mathrm{r}}}{2}$

The overall heat transfer coefficient of evaporator (UA), is found with the following equation:

$$
\mathrm{UA}=\frac{\mathrm{q}_{\mathrm{m}}}{\Delta \mathrm{T}_{\mathrm{m}}}
$$

Here, $\Delta \mathrm{T}_{\mathrm{m}}$ is logarithmic mean temperature difference and is presented in Eq. (6) below:

$$
\Delta T_{m}=\frac{\left(T_{a i}-T_{r o}\right)-\left(T_{a o}-T_{r i}\right)}{\operatorname{In}\left(\frac{\left(T_{a i}-T_{r o}\right)}{\left(T_{a o}-T_{r i}\right)}\right)}
$$

where, $\mathrm{T}_{\mathrm{ai}}$ and $\mathrm{T}_{\mathrm{a}}$ are the inlet and outlet temperatures of air to and from the heat exchanger respectively. Here $\mathrm{T}_{\text {ria }}$ and $\mathrm{T}_{\mathrm{ro}}$ are the inlet and outlet temperatures of refrigerant to and from the heat exchanger respectively.

\section{Developed fuzzy expert system for the performance of finned tube evaporator under frosting conditions}

Fuzzy logic is a superset of Boolean-conventional logic that has been expanded to handle the concept of partial truth and truth values between "completely true" and "completely false". Fuzzy theory should be seen as a methodology to generalize any specific theory from crisp to continuous. Fuzzy modeling opens the possibility for straightforward translation of statements in natural language (verbal formulation) of the observed problem into a fuzzy system. Its functioning is based on mathematical tools $[6,7]$. There are two types of fuzzy inference systems in the toolbox: Mamdani-type and Sugeno-type. These two types of inference systems vary somewhat in the way outputs are determined. Fuzzy 
Table 1. Fuzzy sets of input and output variables.

\begin{tabular}{|l|c|l|l|l|l|l|l|}
\hline $\begin{array}{l}\text { Membership } \\
\text { name }\end{array}$ & \multicolumn{3}{|c|}{$\mathrm{T}_{\mathrm{a}}\left({ }^{\circ} \mathrm{C}\right)$} & \multicolumn{2}{c|}{$\mathrm{u}_{\mathrm{a}}\left(\mathrm{ms}^{-1}\right)$} & \multicolumn{2}{c|}{$\mathrm{UA}\left(\mathrm{W}^{\circ} \mathrm{C}^{-1}\right)$} \\
\hline Very Low & $\mathrm{L} 1$ & $\mathrm{~T}_{\mathrm{a} 1}$ & $\begin{array}{l}1.17- \\
2.83\end{array}$ & $\mathrm{u}_{\mathrm{a} 1}$ & $\begin{array}{l}0.34- \\
1.66\end{array}$ & $\mathrm{UA}_{1}$ & $\begin{array}{l}15.97- \\
23.61\end{array}$ \\
\hline Low & $\mathrm{L} 2$ & $\mathrm{~T}_{\mathrm{a} 2}$ & $2-3.66$ & $\mathrm{u}_{\mathrm{a} 2}$ & $1-2.32$ & $\mathrm{UA}_{2}$ & $\begin{array}{l}19.79- \\
27.43\end{array}$ \\
\hline $\begin{array}{l}\text { Negative } \\
\text { Medium }\end{array}$ & $\mathrm{L} 3$ & $\mathrm{~T}_{\mathrm{a} 3}$ & $\begin{array}{l}2.83- \\
4.49\end{array}$ & $\mathrm{u}_{\mathrm{a} 3}$ & $\begin{array}{l}1.66- \\
2.98\end{array}$ & $\mathrm{UA}_{3}$ & $\begin{array}{l}23.61- \\
31.25\end{array}$ \\
\hline Medium & $\mathrm{L} 4$ & $\mathrm{~T}_{\mathrm{a} 4}$ & $\begin{array}{l}3.66- \\
5.32\end{array}$ & $\mathrm{u}_{\mathrm{a} 4}$ & $\begin{array}{l}2.32- \\
3.64\end{array}$ & $\mathrm{UA}_{4}$ & $\begin{array}{l}27.43- \\
35.07\end{array}$ \\
\hline $\begin{array}{l}\text { Positive } \\
\text { Medium }\end{array}$ & $\mathrm{L} 5$ & $\mathrm{~T}_{\mathrm{a} 5}$ & $\begin{array}{l}4.49- \\
6.15\end{array}$ & $\mathrm{u}_{\mathrm{a} 5}$ & $\begin{array}{l}2.98- \\
4.3\end{array}$ & $\mathrm{UA}_{5}$ & $\begin{array}{l}31.25- \\
38.89\end{array}$ \\
\hline High & $\mathrm{L} 6$ & $\mathrm{~T}_{\mathrm{a} 6}$ & $\begin{array}{l}5.32- \\
6.98\end{array}$ & $\mathrm{u}_{\mathrm{a} 6}$ & $\begin{array}{l}3.64- \\
4.96\end{array}$ & $\mathrm{UA}_{6}$ & $\begin{array}{l}35.07- \\
42.71\end{array}$ \\
\hline Very High & $\mathrm{L} 7$ & $\mathrm{~T}_{\mathrm{a} 7}$ & $\begin{array}{l}6.15- \\
7.81\end{array}$ & $\mathrm{u}_{\mathrm{a} 7}$ & $\begin{array}{l}4.3- \\
5.62\end{array}$ & $\mathrm{UA}_{7}$ & $\begin{array}{l}38.89- \\
46.53\end{array}$ \\
\hline
\end{tabular}

Table 2. Actual data (rule, training)

\begin{tabular}{|c|c|c|c|c|c|c|c|}
\hline No & \begin{tabular}{c|}
$\mathbf{T}_{\mathrm{a}}$ \\
$\left({ }^{\circ} \mathbf{C}\right)$
\end{tabular} & $\begin{array}{c}\mathbf{u}_{\mathrm{a}} \\
\left(\mathrm{ms}^{-1}\right)\end{array}$ & $\begin{array}{r}\text { Rule, } \\
\text { Rule \# }\end{array}$ & No & $\begin{array}{c}\mathbf{T}_{\mathbf{a}} \\
\left({ }^{\circ} \mathbf{C}\right)\end{array}$ & $\begin{array}{c}\mathbf{u}_{\mathrm{a}} \\
\left(\mathrm{ms}^{-1}\right)\end{array}$ & $\begin{array}{c}\text { Rule, } \\
\text { Rule \# }\end{array}$ \\
\hline 1 & 2 & ua1 & $\mathrm{x},(1)$ & 6 & 2 & ua4 & $\mathrm{x},(6)$ \\
\hline 31 & 3 & ua1 & $\mathrm{x},(11)$ & 36 & 3 & ua4 & $\mathrm{x},(16)$ \\
\hline 61 & 4 & ua1 & $\mathrm{x},(21)$ & 66 & 4 & ua4 & $\mathrm{x},(26)$ \\
\hline 71 & 4.5 & ua1 & $\mathrm{x},(31)$ & 76 & 4.5 & ua4 & $\mathrm{x},(36)$ \\
\hline 91 & 5 & ua1 & $\mathrm{x},(41)$ & 96 & 5 & ua4 & $\mathrm{x},(46)$ \\
\hline 121 & 6 & ua1 & $\mathrm{x},(51)$ & 126 & 6 & ua4 & $\mathrm{x},(56)$ \\
\hline 151 & 7 & ua1 & $\mathrm{x},(61)$ & 156 & 7 & ua4 & $\mathrm{x},(66)$ \\
\hline 2 & 2 & ua1 & $\mathrm{x},(2)$ & 7 & 2 & ua5 & $\mathrm{x},(7)$ \\
\hline 32 & 3 & ua1 & $\mathrm{x},(12)$ & 37 & 3 & ua5 & $\mathrm{x},(17)$ \\
\hline 62 & 4 & ua1 & $\mathrm{x},(22)$ & 67 & 4 & ua5 & $\mathrm{x},(27)$ \\
\hline 72 & 4.5 & ua1 & $\mathrm{x},(32)$ & 77 & 4.5 & ua5 & $\mathrm{x},(37)$ \\
\hline 92 & 5 & ua1 & $\mathrm{x},(42)$ & 97 & 5 & ua5 & $\mathrm{x},(47)$ \\
\hline 122 & 6 & ua1 & $\mathrm{x},(52)$ & 127 & 6 & ua5 & $\mathrm{x},(57)$ \\
\hline 152 & 7 & ua1 & $\mathrm{x},(62)$ & 157 & 7 & ua5 & $\mathrm{x},(67)$ \\
\hline 3 & 2 & ua2 & $\mathrm{x},(3)$ & 8 & 2 & ua6 & $\mathrm{x},(8)$ \\
\hline 33 & 3 & ua2 & $\mathrm{x},(13)$ & 38 & 3 & ua6 & $\mathrm{x},(18)$ \\
\hline 63 & 4 & ua2 & $\mathrm{x},(23)$ & 68 & 4 & ua6 & $\mathrm{x},(28)$ \\
\hline 73 & 4.5 & ua2 & $\mathrm{x},(33)$ & 78 & 4.5 & ua6 & $\mathrm{x},(38)$ \\
\hline 93 & 5 & ua2 & $\mathrm{x},(43)$ & 98 & 5 & ua6 & $\mathrm{x},(48)$ \\
\hline 123 & 6 & ua2 & $\mathrm{x},(53)$ & 128 & 6 & ua6 & $\mathrm{x},(58)$ \\
\hline 153 & 7 & ua2 & $\mathrm{x},(63)$ & 158 & 7 & ua6 & $\mathrm{x},(68)$ \\
\hline 4 & 2 & ua3 & $\mathrm{x},(4)$ & 9 & 2 & ua6 & $\mathrm{x},(9)$ \\
\hline 34 & 3 & ua3 & $\mathrm{x},(14)$ & 39 & 3 & ua6 & $\mathrm{x},(19)$ \\
\hline 64 & 4 & ua3 & $\mathrm{x},(24)$ & 69 & 4 & ua6 & $\mathrm{x},(29)$ \\
\hline 74 & 4.5 & ua3 & $\mathrm{x},(34)$ & 79 & 4.5 & ua6 & $\mathrm{x},(39)$ \\
\hline 94 & 5 & ua3 & $\mathrm{x},(44)$ & 99 & 5 & ua6 & $\mathrm{x},(49)$ \\
\hline 124 & 6 & ua3 & $\mathrm{x},(54)$ & 129 & 6 & ua6 & $\mathrm{x},(59)$ \\
\hline 154 & 7 & ua3 & $\mathrm{x},(64)$ & 159 & 7 & ua6 & $\mathrm{x},(69)$ \\
\hline 5 & 2 & ua4 & $\mathrm{x},(5)$ & 10 & 2 & ua7 & $\mathrm{x},(10)$ \\
\hline 35 & 3 & ua4 & $\mathrm{x},(15)$ & 40 & 3 & ua7 & $\mathrm{x},(20)$ \\
\hline 65 & 4 & ua4 & $\mathrm{x},(25)$ & 70 & 4 & ua7 & $\mathrm{x},(30)$ \\
\hline 75 & 4.5 & ua4 & $\mathrm{x},(35)$ & 80 & 4.5 & ua7 & $\mathrm{x},(40)$ \\
\hline 95 & 5 & ua4 & $\mathrm{x},(45)$ & 100 & 5 & ua7 & $\mathrm{x},(50)$ \\
\hline 125 & 6 & ua4 & $\mathrm{x},(55)$ & 130 & 6 & ua7 & $\mathrm{x},(60)$ \\
\hline 155 & 7 & ua4 & $\mathrm{x},(65)$ & 160 & 7 & ua7 & $\mathrm{x},(70)$ \\
\hline
\end{tabular}

Table 3. Actual data (test)

\begin{tabular}{|l|l|l|l|l|l|}
\hline $\mathbf{N o}$ & $\left.\mathbf{T}_{\mathbf{a}}{ }^{\mathbf{}} \mathbf{C}\right)$ & $\mathbf{u}_{\mathbf{a}}\left(\mathbf{m s}^{-1}\right)$ & $\mathbf{N o}$ & $\mathbf{T}_{\mathbf{a}}\left({ }^{\mathbf{}} \mathbf{C}\right)$ & $\mathbf{u}_{\mathbf{a}}\left(\mathbf{m s}^{-1}\right)$ \\
\hline 11 & 2.5 & 1 & 46 & 3.5 & 3.2 \\
\hline 41 & 3.5 & 1 & 106 & 5.5 & 3.2 \\
\hline 101 & 5.5 & 1 & 136 & 6.5 & 3.2 \\
\hline 131 & 6.5 & 1 & 17 & 2.5 & 3.64 \\
\hline 12 & 2.5 & 1.44 & 47 & 3.5 & 3.64 \\
\hline 42 & 3.5 & 1.44 & 107 & 5.5 & 3.64 \\
\hline 102 & 5.5 & 1.44 & 137 & 6.5 & 3.64 \\
\hline 132 & 6.5 & 1.44 & 18 & 2.5 & 4.08 \\
\hline 13 & 2.5 & 1.88 & 48 & 3.5 & 4.08 \\
\hline 43 & 3.5 & 1.88 & 108 & 5.5 & 4.08 \\
\hline 103 & 5.5 & 1.88 & 138 & 6.5 & 4.08 \\
\hline 133 & 6.5 & 1.88 & 19 & 2.5 & 4.52 \\
\hline 14 & 2.5 & 2.32 & 49 & 3.5 & 4.52 \\
\hline 44 & 3.5 & 2.32 & 109 & 5.5 & 4.52 \\
\hline 104 & 5.5 & 2.32 & 139 & 6.5 & 4.52 \\
\hline 134 & 6.5 & 2.32 & 20 & 2.5 & 4.96 \\
\hline 15 & 2.5 & 2.76 & 50 & 3.5 & 4.96 \\
\hline 45 & 3.5 & 2.76 & 110 & 5.5 & 4.96 \\
\hline 105 & 5.5 & 2.76 & 140 & 6.5 & 4.96 \\
\hline 16 & 2.5 & 3.2 & & & \\
\hline & & & & & \\
\hline
\end{tabular}

Table 4. Predicted values

\begin{tabular}{|l|l|l|l|l|l|}
\hline $\mathbf{N o}$ & $\mathbf{T}_{\mathbf{a}}\left({ }^{\mathbf{}} \mathbf{C}\right)$ & $\mathbf{u}_{\mathbf{a}}\left(\mathbf{m s}^{-1}\right)$ & $\mathbf{N o}$ & $\mathbf{T}_{\mathbf{a}}\left({ }^{\mathbf{}} \mathbf{C}\right)$ & $\mathbf{u}_{\mathbf{a}}\left(\mathbf{m s}^{-1}\right)$ \\
\hline 21 & 2.75 & 1 & 26 & 2.75 & 3.2 \\
\hline 51 & 3.75 & 1 & 56 & 3.75 & 3.2 \\
\hline 81 & 4.75 & 1 & 86 & 4.75 & 3.2 \\
\hline 111 & 5.75 & 1 & 116 & 5.75 & 3.2 \\
\hline 22 & 2.75 & 1.44 & 27 & 2.75 & 3.64 \\
\hline 52 & 3.75 & 1.44 & 57 & 3.75 & 3.64 \\
\hline 82 & 4.75 & 1.44 & 87 & 4.75 & 3.64 \\
\hline 112 & 5.75 & 1.44 & 117 & 5.75 & 3.64 \\
\hline 23 & 2.75 & 1.88 & 28 & 2.75 & 4.08 \\
\hline 53 & 3.75 & 1.88 & 58 & 3.75 & 4.08 \\
\hline 83 & 4.75 & 1.88 & 88 & 4.75 & 4.08 \\
\hline 113 & 5.75 & 1.88 & 118 & 5.75 & 4.08 \\
\hline 24 & 2.75 & 2.32 & 29 & 2.75 & 4.52 \\
\hline 54 & 3.75 & 2.32 & 59 & 3.75 & 4.52 \\
\hline 84 & 4.75 & 2.32 & 89 & 4.75 & 4.52 \\
\hline 114 & 5.75 & 2.32 & 119 & 5.75 & 4.52 \\
\hline 25 & 2.75 & 2.76 & 30 & 2.75 & 4.96 \\
\hline 55 & 3.75 & 2.76 & 60 & 3.75 & 4.96 \\
\hline 85 & 4.75 & 2.76 & 120 & 5.75 & 4.96 \\
\hline 115 & 5.75 & 2.76 & & & \\
\hline
\end{tabular}

inference systems have been successfully applied in fields such as automatic control, data classification, decision analysis, expert systems, and computer vision. Because of its multidisciplinary nature, fuzzy inference systems are associated with a number of names, such as fuzzy-rulebased systems, fuzzy expert systems, fuzzy modeling, fuzzy associative memory, fuzzy logic controllers, and simply (and ambiguously) fuzzy systems [8].

In this study, thermal performance of a finned tube heat exchanger under frost forming operating conditions was modeled with the RBMTF technique. With this aim, the data obtained from the experimental study were used. This 
stimulus model is constructed into rule-based Mamdanitype fuzzy modeling, using input parameters as $\mathrm{T}_{\mathrm{a}}, \mathrm{u}_{\mathrm{a}}$ and output parameter as UA, described by RBMTF if-then rules (Figure 2). RBMTF has been designed using the MATLAB R2010b fuzzy logic toolbox. Classification of the variables into a specified number of subsets depends on the nature of the problem. The inputs $T_{a}$ and $u_{a}$ together with the output UA were categorized into 7 subsets and their triangle membership functions were determined. The membership functions are presented in Figures 3 and 4. The membership functions were developed for the study, representing Very Low (L1), Low (L2), Negative Medium (L3), Medium (L4), Positive Medium (L5), High (L6), and Very High (L7) linguistic classes (Table 1).

In this study, the data set included 110 data (training+ test data). 70 of them were chosen as training data (Table 2), whereas 40 of them were chosen for the test data (Table 3 ). Values of prediction consist of 50 sets (Table 4).

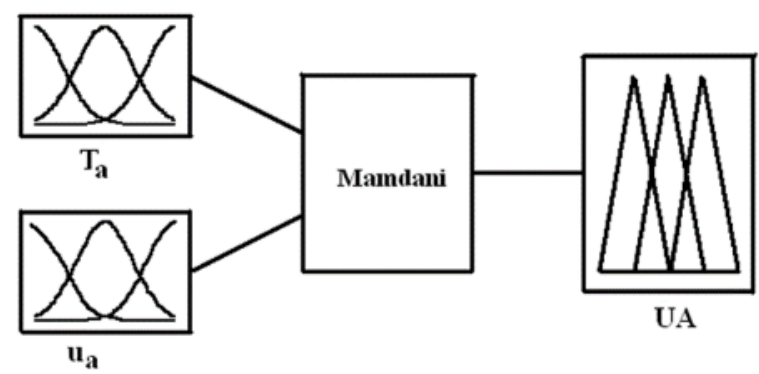

Figure 2. Designed fuzzy modeling structure the performance of a finned tube evaporator operating under snowing conditions

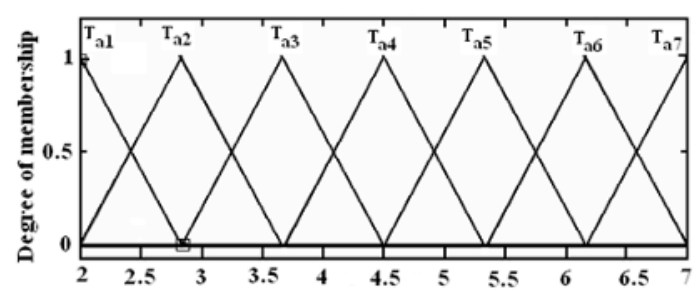

(a)

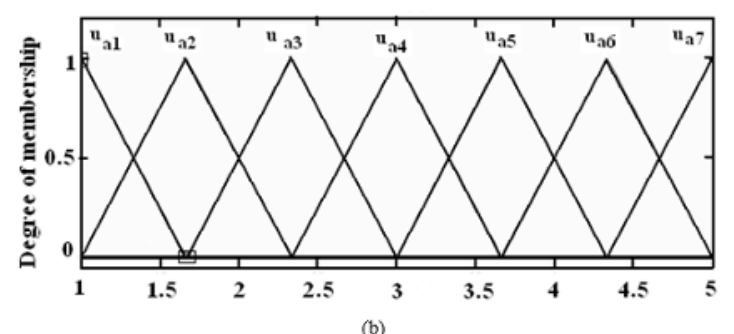

Figure 3. Fuzzy membership functions for two input variables: (a) $\mathrm{T}_{\mathrm{a}}$ fuzzy sets graphics; (b) $\mathrm{u}_{\mathrm{a}}$ fuzzy sets graphics.

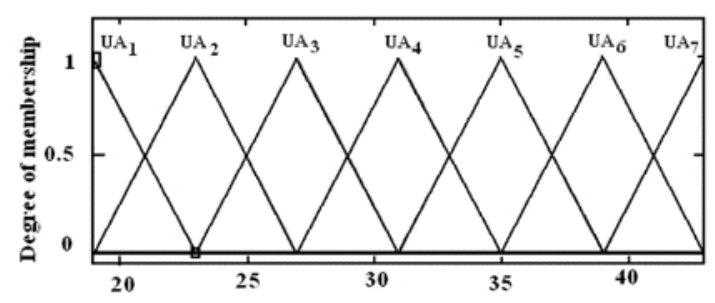

Figure 4. Fuzzy membership functions for one output variable: UA fuzzy set graphic.
Fuzzy membership functions in analytical form are expressed in Eqs. (7) -(10) for UA.

$$
\begin{aligned}
& U A(x)=\left\{\begin{array}{ll}
x ; & 19.79 \leq x \leq 42.71 \\
0 ; & \text { otherwise }
\end{array}\right\} \\
& \mu_{\mathrm{UAl}}(\mathrm{x})=\left\{\begin{array}{ll}
0 ; & \text { otherwise } \\
\frac{23.61-\mathrm{x}}{3.82} & \text { if } 19.79 \leq \mathrm{x} \leq 23.61
\end{array}\right\} \\
& \mu_{\mathrm{UA} 4}(\mathrm{x})=\left\{\begin{array}{ll}
\frac{0 ;}{3.82} & \text { if } 27.43<\mathrm{x} \leq 31.25 \\
\frac{35.07-\mathrm{x}}{3.82} & \text { if } 31.25<\mathrm{x} \leq 35.07 \\
0 ; & \mathrm{x} \geq 35.07
\end{array}\right\} \\
& \mu_{\mathrm{UA} 7}(\mathrm{x})=\left\{\begin{array}{ll}
0 ; & \text { otherwise } \\
\frac{4271-\mathrm{x}}{3.82} & \text { if } 3889<\mathrm{x} \leq 4271
\end{array}\right\}
\end{aligned}
$$

Where $\mu_{\mathrm{UA} 1}(\mathrm{x})$ is the membership function for $\mathrm{UA}_{1}=$ 15.97-23.61 $\mathrm{W}^{\circ} \mathrm{C}^{-1}, \mu_{\mathrm{UA} 4}(\mathrm{x})$ is the membership function for $\mathrm{UA}_{4}=27.43-35.07 \mathrm{~W}^{\circ} \mathrm{C}^{-1}, \mu_{\mathrm{UA}}(\mathrm{x})$ represents the membership function for $\mathrm{UA}_{7}=38.89-46.53 \mathrm{~W}{ }^{\circ} \mathrm{C}^{-1}$. Where, $\mathrm{UA}_{1}, \mathrm{UA}_{4}$ and $\mathrm{UA}_{7}$ variables are fuzzificated as linguistic variables. An advanced RBMTF model was used for unperformed actual data. $\mathrm{T}_{\mathrm{a}}$ and $\mathrm{u}_{\mathrm{a}}$ values were predicted because modeling of the necessary UA was made.

\section{Results and discussion}

If there the surface temperature of evaporators in refrigerating systems, is lower than the freezing point of the water vapor in the air, then a frost film forms on the evaporator surfaces, first; and in case the frost surface temperature continues to be lower than the freezing point, then the frost accumulates over the surface and acts as an insulating agent. Since this situation will increase thermal resistance, the amount of heat absorbed by the refrigerant will decrease, the inter-fin distances will narrow due to the frost accumulation and ultimately, energy consumption will increase [1]. In this study, RBMTF technique has been used to model the performance of a finned tube evaporator at the transient regime for 4 situations and with different $\mathrm{u}_{\mathrm{a}}$ values. The findings of this study are presented below:

$>$ Situation for $\mathrm{u}_{\mathrm{a}}=1 ; 1.44 ; 1.88 \mathrm{~m} \mathrm{~s}^{-1}: \mathrm{T}_{\mathrm{a}}=2-7^{\circ} \mathrm{C}$. Number of fuzzy rules=21 (Table 5). Number of RBMTF tests $=12$. Number of RBMTF prediction $=15 . \quad \mathrm{UA}_{\max }=42.7 \quad \mathrm{~W}^{\circ} \mathrm{C}^{-1} \quad$ (actual) ; $\mathrm{UA}_{\min }=30.1 \quad \mathrm{~W}^{\circ} \mathrm{C}^{-1}$ (actual); $\mathrm{UA}_{\max }=41.5 \mathrm{~W}^{\circ} \mathrm{C}^{-1}$ (test); $\mathrm{UA}_{\min }=30.9 \mathrm{~W}^{\circ} \mathrm{C}^{-1}$ (test); $\mathrm{UA}_{\max }=39 \mathrm{~W}^{\circ} \mathrm{C}^{-1}$ (prediction); $\mathrm{UA}_{\min }=29.6 \mathrm{~W}^{\circ} \mathrm{C}^{-1}$ (prediction) (Figure 5).

$>$ Situation for $\mathrm{u}_{\mathrm{a}}=2.32 ; 2.76 \mathrm{~m} \mathrm{~s}-1: \mathrm{T}_{\mathrm{a}}=2-7 \mathrm{oC}$. Number of fuzzy rules=14 (Table 6). Number of RBMTF 
tests $=8$. Number of RBMTF prediction $=10$. $\mathrm{UA}_{\max }=38.7 \quad \mathrm{~W}^{\circ} \mathrm{C}^{-1} \quad$ (actual) ; $\mathrm{UA}_{\min }=27.2 \mathrm{~W}^{\circ} \mathrm{C}^{-1}$ (actual); $\mathrm{UA}_{\max }=37.5 \mathrm{WoC}-1$ (test); $\mathrm{UA}_{\min }=28 \mathrm{~W}^{\circ} \mathrm{C}^{-}$ $1 \quad$ (test); $\quad \mathrm{UA}_{\max }=35.5 \quad \mathrm{~W}^{\circ} \mathrm{C}^{-1} \quad$ (prediction); $\mathrm{UA}_{\min }=28.43 \mathrm{~W}^{\circ} \mathrm{C}^{-1}$ (prediction) $($ Figure 6$)$.

Situation for $\mathrm{u}_{\mathrm{a}}=3.2 ; 3.64 \mathrm{~m} \mathrm{~s}-1$. Ta=2-7oC. Number of fuzzy rules=14 (Table 7). Number of RBMTF tests $=8$. Number of RBMTF prediction $=10$. $\mathrm{UA}_{\max }=36.1 \mathrm{~W}^{\circ} \mathrm{C}^{-1} \quad$ (actual) ; $\mathrm{UA}_{\min }=24.2 \mathrm{~W}^{\circ} \mathrm{C}^{-1}$ (actual) ; $\mathrm{UA}_{\max }=34.9 \mathrm{~W}^{\circ} \mathrm{C}^{-1}$ (test) ; $\mathrm{UA}_{\min }=25.1$ $\mathrm{W}^{\circ} \mathrm{C}^{-1}$ (test); $\mathrm{UA}_{\max }=34.2 \quad \mathrm{~W}^{\circ} \mathrm{C}^{-1} \quad$ (prediction); $\mathrm{UA}_{\min }=24.3 \mathrm{~W}^{\circ} \mathrm{C}^{-1}$ (prediction) ( Figure 7).

Situation for $\mathrm{u}_{\mathrm{a}}=4.08 ; 4.52 ; 4.96 \mathrm{~m} \mathrm{~s}-1 . \mathrm{T}_{\mathrm{a}}=2-7 \mathrm{oC}$. Number of fuzzy rules $=21$ (Table 8). Number of RBMTF tests $=12$. Number of RBMTF prediction $=15 . \quad \mathrm{UA}_{\max }=33.4 \quad \mathrm{~W}^{\circ} \mathrm{C}^{-1} \quad$ (actual) ; $\mathrm{UA}_{\min }=19.8 \mathrm{~W}^{\circ} \mathrm{C}^{-1}$ (actual) ; UAmax $=32.2 \mathrm{~W}^{\circ} \mathrm{C}^{-1}$ (test) $; \mathrm{UA}_{\min }=20.7 \mathrm{~W}^{\circ} \mathrm{C}^{-1}$ (test) $; \mathrm{UA}_{\max }=31.6 \mathrm{~W}^{\circ} \mathrm{C}^{-1}$ (prediction); UAmin $=21.9 \quad \mathrm{WoC}-1 \quad$ (prediction) (Figure 8).

Table 5. Rules of RBMTF for UA (situation for $\mathrm{u}_{\mathrm{a}}=1 ; 1.44 ; 1.88 \mathrm{~m} \mathrm{~s}^{-1}$ )

\begin{tabular}{|c|c|c|c|c|c|c|}
\hline Rule \# & If & $T_{a}$ & and & $u_{a}$ & then & $U A$ \\
\hline 1 & If & $T_{a}$ is $T_{a 1}$ & and & $u_{a} i s u_{a 1}$ & then & $U A$ is $U A_{7}$ \\
\hline 11 & If & $T_{a}$ is $T_{a 2}$ & and & $u_{a}$ is $u_{a 1}$ & then & $U A$ is $U A_{6}$ \\
\hline 21 & If & $T_{a}$ is $T_{a 3}$ & and & $u_{a}$ is $u_{a 1}$ & then & $U A$ is $U A_{6}$ \\
\hline 31 & If & $T_{a}$ is $T_{a 4}$ & and & $u_{a}$ is $u_{a 1}$ & then & $U A$ is $U A_{6}$ \\
\hline 41 & If & $T_{a}$ is $T_{a 5}$ & and & $u_{a}$ is $u_{a 1}$ & then & $U A$ is $U A_{5}$ \\
\hline 51 & If & $T_{a}$ is $T_{a 6}$ & and & $u_{a}$ is $u_{a 1}$ & then & $U A$ is $U A_{5}$ \\
\hline 61 & If & $T_{a}$ is $T_{a 7}$ & and & $u_{a}$ is $u_{a 1}$ & then & $U A$ is $U A_{5}$ \\
\hline 2 & If & $T_{a}$ is $T_{a 1}$ & and & $u_{a}$ is $u_{a 1}$ & then & $U A$ is $U A_{7}$ \\
\hline 12 & If & $T_{a}$ is $T_{a 2}$ & and & $u_{a} i s u_{a 1}$ & then & $U A$ is $U A_{6}$ \\
\hline 22 & If & $T_{a}$ is $T_{a 3}$ & and & $u_{a}$ is $u_{a 1}$ & then & $U A$ is $U A_{5}$ \\
\hline 32 & If & $T_{a}$ is $T_{a 4}$ & and & $u_{a}$ is $u_{a 1}$ & then & $U A$ is $U A_{5}$ \\
\hline 42 & If & $T_{a}$ is $T_{a 5}$ & and & $u_{a}$ is $u_{a 1}$ & then & $U A$ is $U A_{5}$ \\
\hline 52 & If & $T_{a}$ is $T_{a 6}$ & and & $u_{a}$ is $u_{a 1}$ & then & $U A$ is $U A_{5}$ \\
\hline 62 & If & $T_{a}$ is $T_{a 7}$ & and & $u_{a}$ is $u_{a 1}$ & then & $U A$ is $U A_{4}$ \\
\hline 3 & If & $T_{a}$ is $T_{a 1}$ & and & $u_{a} i s u_{a 2}$ & then & $U A$ is $U A_{6}$ \\
\hline 13 & If & $T_{a}$ is $T_{a 2}$ & and & $u_{a}$ is $u_{a 2}$ & then & $U A$ is $U A_{6}$ \\
\hline 23 & If & $T_{a}$ is $T_{a 3}$ & and & $u_{a}$ is $u_{a 2}$ & then & $U A$ is $U A_{5}$ \\
\hline 33 & If & $T_{a}$ is $T_{a 4}$ & and & $u_{a}$ is $u_{a 2}$ & then & $U A$ is $U A_{5}$ \\
\hline 43 & If & $T_{a}$ is $T_{a 5}$ & and & $u_{a}$ is $u_{a 2}$ & then & $U A$ is $U A_{5}$ \\
\hline 53 & If & $T_{a}$ is $T_{a 6}$ & and & $u_{a}$ is $u_{a 2}$ & then & $U A$ is $U A_{4}$ \\
\hline 63 & If & $T_{a}$ is $T_{a 7}$ & and & $u_{a}$ is $u_{a 2}$ & then & $U A$ is $U A_{4}$ \\
\hline
\end{tabular}

Table 6. Rules of RBMTF for UA

(situation for $\mathrm{u}_{\mathrm{a}}=2.32 ; 2.76 \mathrm{~m} \mathrm{~s}^{-1}$ )

\begin{tabular}{|l|l|l|l|l|l|l|}
\hline Rule \# & If & $T_{a}$ & and & $u_{a}$ & then & UA \\
\hline 4 & If & $T_{a}$ is $T_{a 1}$ & and & $u_{a}$ is $u_{a 3}$ & then & UA is $U A_{6}$ \\
\hline 14 & If & $T_{a}$ is $T_{a 2}$ & and & $u_{a}$ is $u_{a 3}$ & then & UA is $U A_{5}$ \\
\hline 24 & If & $T_{a}$ is $T_{a 3}$ & and & $u_{a}$ is $u_{a 3}$ & then & UA is $U A_{5}$ \\
\hline 34 & If & $T_{a}$ is $T_{a 4}$ & and & $u_{a}$ is $u_{a 3}$ & then & UA is $U A_{5}$ \\
\hline 44 & If & $T_{a}$ is $T_{a 5}$ & and & $u_{a}$ is $u_{a 3}$ & then & UA is $U A_{4}$ \\
\hline 54 & If & $T_{a}$ is $T_{a 6}$ & and & $u_{a}$ is $u_{a 3}$ & then & UA is $U A_{4}$ \\
\hline 64 & If & $T_{a}$ is $T_{a 7}$ & and & $u_{a}$ is $u_{a 3}$ & then & UA is $U A_{3}$ \\
\hline 5 & If & $T_{a}$ is $T_{a 1}$ & and & $u_{a}$ is $u_{a 4}$ & then & UA is $U A_{6}$ \\
\hline 15 & If & $T_{a}$ is $T_{a 2}$ & and & $u_{a}$ is $u_{a 4}$ & then & UA is $U A_{5}$ \\
\hline 25 & If & $T_{a}$ is $T_{a 3}$ & and & $u_{a}$ is $u_{a 4}$ & then & UA is $U A_{4}$ \\
\hline 35 & If & $T_{a}$ is $T_{a 4}$ & and & $u_{a}$ is $u_{a 4}$ & then & UA is $U A_{4}$ \\
\hline 45 & If & $T_{a}$ is $T_{a 5}$ & and & $u_{a}$ is $u_{a 4}$ & then & UA is $U A_{4}$ \\
\hline 55 & If & $T_{a}$ is $T_{a 6}$ & and & $u_{a}$ is $u_{a 4}$ & then & UA is $U A_{3}$ \\
\hline 65 & If & $T_{a}$ is $T_{a 7}$ & and & $u_{a}$ is $u_{a 4}$ & then & UA is $U A_{3}$ \\
\hline
\end{tabular}

Table 7. Rules of RBMTF for UA

(situation for $\mathrm{u}_{\mathrm{a}}=3.2 ; 3.64 \mathrm{~m} \mathrm{~s}^{-1}$ )

\begin{tabular}{|l|l|l|l|l|l|l|}
\hline $\begin{array}{l}\text { Rule } \\
\#\end{array}$ & If & $T_{a}$ & and & $u_{a}$ & then & UA \\
\hline 6 & If & $T_{a}$ is $T_{a 1}$ & and & $u_{a}$ is $u_{a 4}$ & then & UA is $U A_{5}$ \\
\hline 16 & If & $T_{a}$ is $T_{a 2}$ & and & $u_{a}$ is $u_{a 4}$ & then & UA is $U A_{5}$ \\
\hline 26 & If & $T_{a}$ is $T_{a 3}$ & and & $u_{a}$ is $u_{a 4}$ & then & UA is $U A_{4}$ \\
\hline 36 & If & $T_{a}$ is $T_{a 4}$ & and & $u_{a}$ is $u_{a 4}$ & then & UA is $U A_{4}$ \\
\hline 46 & If & $T_{a}$ is $T_{a 5}$ & and & $u_{a}$ is $u_{a 4}$ & then & UA is $U A_{3}$ \\
\hline 56 & If & $T_{a}$ is $T_{a 6}$ & and & $u_{a}$ is $u_{a 4}$ & then & UA is $U A_{3}$ \\
\hline 66 & If & $T_{a}$ is $T_{a 7}$ & and & $u_{a}$ is $u_{a 4}$ & then & UA is $U A_{3}$ \\
\hline 7 & If & $T_{a}$ is $T_{a 1}$ & and & $u_{a}$ is $u_{a 5}$ & then & $U A$ is $U A_{5}$ \\
\hline 17 & If & $T_{a}$ is $T_{a 2}$ & and & $u_{a}$ is $u_{a 5}$ & then & $U A$ is $U A_{4}$ \\
\hline 27 & If & $T_{a}$ is $T_{a 3}$ & and & $u_{a}$ is $u_{a 5}$ & then & $U A$ is $U A_{4}$ \\
\hline 37 & If & $T_{a}$ is $T_{a 4}$ & and & $u_{a}$ is $u_{a 5}$ & then & $U A$ is $U A_{4}$ \\
\hline 47 & If & $T_{a}$ is $T_{a 5}$ & and & $u_{a}$ is $u_{a 5}$ & then & $U A$ is $U A_{3}$ \\
\hline 57 & If & $T_{a}$ is $T_{a 6}$ & and & $u_{a}$ is $u_{a 5}$ & then & $U A$ is $U A_{3}$ \\
\hline 67 & If & $T_{a}$ is $T_{a 7}$ & and & $u_{a}$ is $u_{a 5}$ & then & $U A$ is $U A_{2}$ \\
\hline
\end{tabular}

Table 8. Rules of RBMTF for UA (situation for $\mathrm{u}_{\mathrm{a}}=4.08 ; 4.52 ; 4.96 \mathrm{~m} \mathrm{~s}^{-1}$ )

\begin{tabular}{|c|c|c|c|c|c|c|}
\hline $\begin{array}{l}\text { Rule } \\
\text { \# }\end{array}$ & If & $T_{a}$ & and & $u_{a}$ & then & $U A$ \\
\hline 8 & If & $T_{a}$ is $T_{a 1}$ & and & $u_{a}$ is $u_{a 6}$ & then & $U A$ is $U A_{5}$ \\
\hline 18 & If & $T_{a}$ is $T_{a 2}$ & and & $u_{a}$ is $u_{a 6}$ & then & $U A$ is $U A_{4}$ \\
\hline 28 & If & $T_{a}$ is $T_{a 3}$ & and & $u_{a}$ is $u_{a 6}$ & then & $U A$ is $U A_{3}$ \\
\hline 38 & If & $T_{a}$ is $T_{a 4}$ & and & $u_{a}$ is $u_{a 6}$ & then & $U A$ is $U A_{3}$ \\
\hline 48 & If & $T_{a}$ is $T_{a 5}$ & and & $u_{a}$ is $u_{a 6}$ & then & $U A$ is $U A_{3}$ \\
\hline 58 & If & $T_{a}$ is $T_{a 6}$ & and & $u_{a}$ is $u_{a 6}$ & then & $U A$ is $U A_{2}$ \\
\hline 68 & If & $T_{a}$ is $T_{a 7}$ & and & $u_{a}$ is $u_{a 6}$ & then & $U A$ is $U A_{2}$ \\
\hline 9 & If & $T_{a}$ is $T_{a 1}$ & and & $u_{a}$ is $u_{a 6}$ & then & $U A$ is $U A_{4}$ \\
\hline 19 & If & $T_{a}$ is $T_{a 2}$ & and & $u_{a}$ is $u_{a 6}$ & then & $U A$ is $U A_{4}$ \\
\hline 29 & If & $T_{a}$ is $T_{a 3}$ & and & $u_{a}$ is $u_{a 6}$ & then & $U A$ is $U A_{3}$ \\
\hline 39 & If & $T_{a}$ is $T_{a 4}$ & and & $u_{a}$ is $u_{a 6}$ & then & $U A$ is $U A_{3}$ \\
\hline 49 & If & $T_{a}$ is $T_{a 5}$ & and & $u_{a}$ is $u_{a 6}$ & then & $U A$ is $U A_{3}$ \\
\hline 59 & If & $T_{a}$ is $T_{a 6}$ & and & $u_{a}$ is $u_{a 6}$ & then & $U A$ is $U A_{2}$ \\
\hline 69 & If & $T_{a}$ is $T_{a 7}$ & and & $u_{a}$ is $u_{a 6}$ & then & $U A$ is $U A_{2}$ \\
\hline 10 & If & $T_{a}$ is $T_{a 1}$ & and & $u_{a}$ is $u_{a 7}$ & then & $U A$ is $U A_{4}$ \\
\hline 20 & If & $T_{a}$ is $T_{a 2}$ & and & $u_{a}$ is $u_{a 7}$ & then & $U A$ is $U A_{3}$ \\
\hline 30 & If & $T_{a}$ is $T_{a 3}$ & and & $u_{a}$ is $u_{a 7}$ & then & $U A$ is $U A_{3}$ \\
\hline 40 & If & $T_{a}$ is $T_{a 4}$ & and & $u_{a}$ is $u_{a 7}$ & then & $U A$ is $U A_{2}$ \\
\hline 50 & If & $T_{a}$ is $T_{a 5}$ & and & $u_{a}$ is $u_{a 7}$ & then & $U A$ is $U A_{2}$ \\
\hline 60 & If & $T_{a}$ is $T_{a 6}$ & and & $u_{a}$ is $u_{a 7}$ & then & $U A$ is $U A_{2}$ \\
\hline 70 & If & $T_{a}$ is $T_{a 7}$ & and & $u_{a}$ is $u_{a 7}$ & then & $U A$ is $U A_{1}$ \\
\hline
\end{tabular}

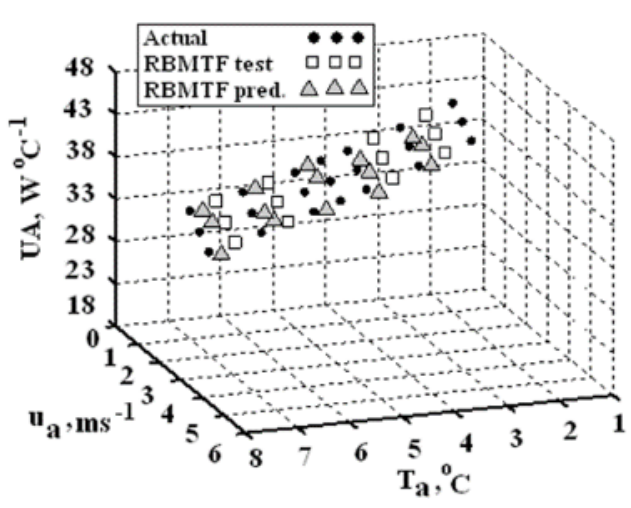

Figure 5. Comparison of actual UA with the UA data obtained from fuzzy technique for $\mathrm{u}_{\mathrm{a}}=1 \mathrm{~ms}^{-1}, \mathrm{u}_{\mathrm{a}}=1.44 \mathrm{~ms}^{-1}, \mathrm{u}_{\mathrm{a}}=1.88 \mathrm{~ms}^{-1}$ 


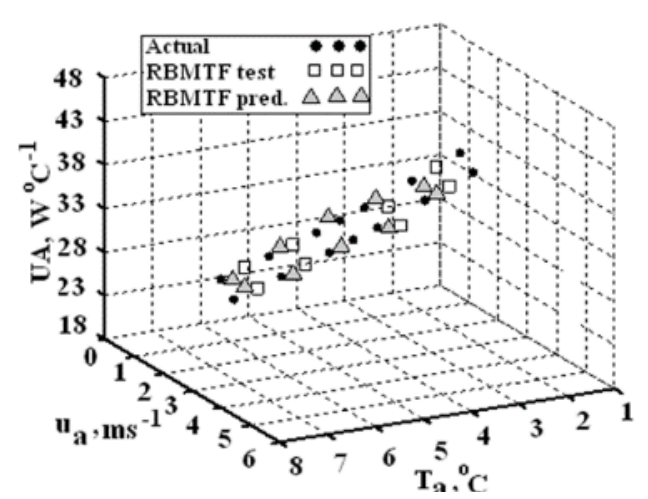

Figure 6. Comparison of actual UA with the UA data obtained from fuzzy technique for $\mathrm{u}_{\mathrm{a}}=2.32 \mathrm{~ms}^{-1}, \mathrm{u}_{\mathrm{a}}=2.76 \mathrm{~ms}^{-1}$

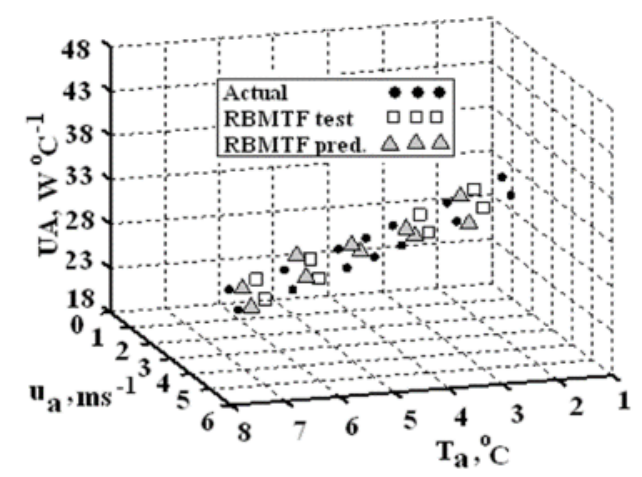

Figure 7. Comparison of actual UA with the UA data obtained from fuzzy technique for $\mathrm{u}_{\mathrm{a}}=3.2 \mathrm{~ms}^{-1}, \mathrm{u}_{\mathrm{a}}=3.64 \mathrm{~ms}^{-1}$

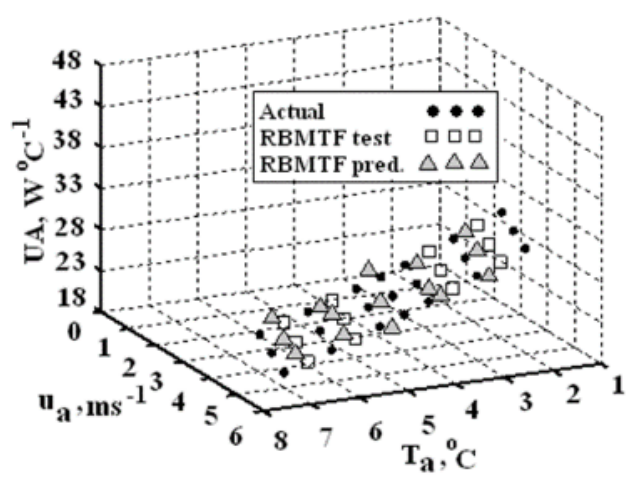

Figure 8. Comparison of actual UA with the UA data obtained from fuzzy technique for $\mathrm{u}_{\mathrm{a}}=4.08 \mathrm{~ms}^{-1}, \mathrm{u}_{\mathrm{a}}=4.96 \mathrm{~ms}^{-1}$

When Figures 5-8 are evaluated together, it is found that, at minimum air inlet speed and minimum temperature $\left(\mathrm{u}_{\mathrm{a}}=1 \mathrm{~ms}^{-1}\right.$ and $\left.\mathrm{T}_{\mathrm{a}}=2^{\circ} \mathrm{C}\right)$, UA is a maximum $\left(\mathrm{UA}_{\max }=42.7\right.$ $\left.\mathrm{W}^{\circ} \mathrm{C}^{-1}\right)$, whereas at maximum air inlet speed and maximum temperature $\left(\mathrm{u}_{\mathrm{a}}=4.96 \mathrm{~m} \mathrm{~s}-1\right.$ and $\left.\mathrm{T}_{\mathrm{a}}=7^{\circ} \mathrm{C}\right)$, UA becomes a minimum $\left(\mathrm{UA}_{\min }=19.8 \mathrm{~W}^{\circ} \mathrm{C}^{-1}\right)$. The increase in the air inlet speed has led to an increase in the amount of moisture in the air. The increase in the amount of water vapor has led ted to the increasing frost layer and hence causing the drop of the total heat transfer in the system.

The error during the learning session is called the rootmean-squared (RMS) value and is defined as follows [9]:

$\operatorname{RMS}=\left((1 / p) \sum_{j}\left|t_{j}-o_{j}\right|^{2}\right)^{1 / 2}$
In addition, the absolute fraction of variance $\left(\mathrm{R}^{2}\right)$ and mean absolute percentage error (MAPE) are defined as follows, respectively [9]:

$R^{2}=1-\left(\frac{\sum_{j}\left(t_{j}-o_{j}\right)^{2}}{\sum_{j}\left(o_{j}\right)^{2}}\right)$

where $t$ is target value, $o$ is output value, and $p$ is pattern [9].

MAPE $=\frac{o-t}{o} \times 100$

The statistical values such as RMS, $\mathrm{R}^{2}$, MAPE, maximum error and minimum error given in Tables 9 and 10 for training and test values. $\mathrm{R}^{2}$ for the training data is $99.91 \%$ and $\mathrm{R}^{2}$ for the test data is $99.91 \%$ (Figure 9). When Tables 7-8 and Figure 9 are studied, it is found that actual values and the values from fuzzy technique are very close to each other.

Table 9. The statistical error values for UA for training

\begin{tabular}{|c|c|c|c|c|}
\hline RMS & $\mathrm{R}^{2}(\%)$ & $\begin{array}{c}\text { MAPE } \\
(\%)\end{array}$ & $\begin{array}{c}\text { Min error } \\
(\%)\end{array}$ & $\begin{array}{c}\text { Max error } \\
(\%)\end{array}$ \\
\hline 0.95 & 99.91 & 0.073 & 0.03 & 7.03 \\
\hline
\end{tabular}

Table 10. The statistical error values for UA for test

\begin{tabular}{|c|c|c|c|c|}
\hline RMS & $\mathrm{R}^{2}(\%)$ & $\begin{array}{c}\text { MAPE } \\
(\%)\end{array}$ & $\begin{array}{c}\text { Min error } \\
(\%)\end{array}$ & $\begin{array}{c}\text { Max error } \\
(\%)\end{array}$ \\
\hline 0.93 & 99.91 & 0.78 & 0.06 & 8.93 \\
\hline
\end{tabular}

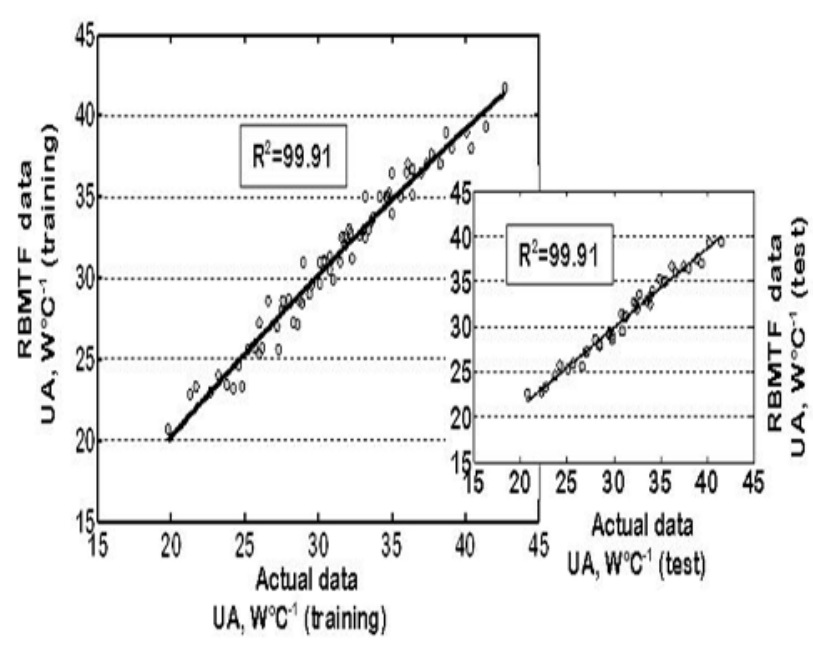

Figure 9. Comparison of the actual and RBMTF results

\section{Conclusion}

Modeling of performance of a finned-tube type evaporator was conducted in this study by making use of the RuleBased Mamdani Type Fuzzy logic technique. The evaporator was made to operate under frost forming conditions and the conclusions drawn in this paper are summarized as follows:

$>$ The RBMTF was trained and tested by means of the MATLAB software on a personal computer.

$>$ Input parameters $\left(\mathrm{T}_{\mathrm{a}}, \mathrm{u}_{\mathrm{a}}\right)$ and output parameter UA, were described by RBMTF if-then rules. 
110 experimental data sets were used, out of which 70 were used in the training step (Table 2) and 40 were for the testing session (Table 3 ).

$>$ The UA values that were not considered with the experimental study were estimated by using the RBMTF (Figs. 5-8 and Table 4).

$>$ The decrease in inlet air temperature has caused only a slight increase in the frost layer and that's why as the inlet air temperature falls the total heat transfer has increased. (Figs.5-8).

$>$ The amount of water vapor in the air has decreased as a result of the decreasing air inlet speed. This has led to an increasing total heat transfer as the air inlet speed fell. (Figs.5-8).

The actual data and RBMTF results show that RBMTF can be successfully used for the modeling of performance of finned tube evaporator under frost conditions. Future studies may use the data obtained in this study and involve other techniques like artificial neural networks (ANN) and genetic algorithm (GA) under different operating conditions to calculate an optimum performance for total heat transfer of a system.

\section{References}

1. D.N. Ozen, Selcuk University Ph.D Thesis, Turkey, (2011)

2. S. H. Liao, Expert Syst. Appl., 28, 93-103, (2005)

3. S. Tasdemir, I. Saritas, M. Ciniviz, N. Allahverdi, Expert Syst. Appl., 38, 13912-13923 (2011)

4. M. Tosun, K. Dincer, Int. J. Refrig, 34, 362-373. (2011)

5. M. Tosun, K. Dincer, S. Baskaya, Expert Syst. Appl., 38, 5553-5560 (2011)

6. K. Dincer, S. Tasdemir, S. Baskaya, I. Ucgul, B. Z. Uysal, Numer. Heat Transfer, Part B 54, 499-517 (2008)

7. M. T. Lah, B. Zupancic, A. Krainer, Build. Environ., 40, 1626-1637, (2005)

8. MathWorks,http://www.mathworks.com/help/toolbo $\mathrm{x} /$ fuzzy/fp351 dup8.html (2012)

9. Sözen, E. Arcaklioğlu, T. Menlik, M. Özalp, Expert Syst. Appl., 36, 4346-4356 (2009) 